\title{
Place Attachment as a Function of Meaning Assignment
}

\author{
H.P. Casakin ${ }^{*}, 1$ and S. Kreitler ${ }^{2}$ \\ ${ }^{1}$ Ariel University Center of Samaria, Department of Architecture, P.O. Box 3, 44837 Ariel, Israel \\ ${ }^{2}$ Department of Psychology, Tel Aviv University, Ramat Aviv, Tel Aviv 69978, Israel
}

\begin{abstract}
By interacting with their environments individuals create bonds and links. In the course of this interaction, anonymous spaces are converted into places endowed with meaning, which serve as objects of attachment. Attachment is defined as a construct representing mainly the emotional bond to a location, but which includes also cognitions and meaning, and is related to personality tendencies of the individual. In this study, information processing tendencies of different aspects of place attachment were investigated. Information processing tendencies were defined in terms of the Meaning Theory that deals with identifying cognitive processes involved in the performance of diverse acts and were assessed by means of the Meaning Test. A focus was set on four aspects of place attachment dealing with: preferences for open or closed spaces, grasping place atmospheres, considering the matching of places to actions, and caring about orientation in space. These attitudes were assessed by a Likert-type questionnaire. The participants were 36 architecture students. Associations between place attachment and information processing tendencies were analyzed by t-tests. Results showed significant and meaningful relations between aspects of place attachment and processing tendencies. Implications for environmental design are proposed.
\end{abstract}

Keywords: Information processing, meaning, attitudes, place attachment.

\section{INTRODUCTION}

In recent years attention has focused increasingly on the relation of human beings to places, environments or geographic locations in general. Investigators of mobility trends, urbanization, preferences for natural settings and other environmental themes have become impressed with the quality and contents of the relation to places [1-5] These observations have led to the conclusion that the relation of people to places is of a particular kind and that it differs from their relation to other objects or aspects of their environment. So much so that the special nature of the human-place bonding came to be referred to by means of a newly coined term "place attachment". A survey of the literature shows that there is no single accepted definition of place attachment. Under the circumstances the second best choice to a definition is focusing on the elements of the concept shared by various investigators. The definition offered by Milligan [6] may well serve this purpose. It views place attachment as an emotional bond formed by an individual to a physical location due to the meaning given to that location through processes of person-environment interactions. There are three major elements that turn this definition into a representative one which may serve as basis for further studies: emotional bond, meaning of the place or site, and interactional processes between the individual and the place.

First, let us focus on the emotional bond. Jorgensen and Stedman [7] have defined place attachment as an emotional

*Address correspondence to this author at the Ariel University Center of Samaria, Department of Architecture, P.O. Box 3, 44837 Ariel, Israel;

E-mail: casakin@bezeqint.net connection of an individual to a physical location. This emotional predisposition can be positive, negative or neutral $[8$, 9]. The second major element is meaning. Places may denote a rich variety of meanings for individuals, for example, meanings of harmony, of peace, of home, of danger or of sanctity [10]. It is likely that the meaning assigned to the place is the trigger for the emotional bond and constitutes the core to which this bond gets attached. The third element is the interactional processes between the individual and the place. These encounters form the framework for the shaping of the meaning of the physical location and enable the emergence of the emotional bond to it.

Two major conclusions about place attachment arise out of the rich and variegated literature about this theme. One is that place attachment includes in addition to emotions also cognitions in the form of various beliefs, attitudes, memories, and concepts evoked by the meaning of place and dependent on interactions with the particular location or the general class of locations of that type (generic attachment) $[11,12]$. The second conclusion is that place attachment has important correlates in the personality and behavior of individuals. Thus, it is related for example to the conception one has of one's past, stability and goals in life [13-15]. Hence, place attachment is in fact embedded in the individual's personality at large and fulfills an important role in regard to such basic characteristics as personal identity [16] and sense of belongingness [17].

To our mind, all the cited elements of place attachment are important: emotion, cognitions, meanings and personality correlates. The purpose of the present study is to apply to the investigation of place attachment the Theory of Meaning $[18,19]$ which would enable binding together the mentioned 
constituents of place attachment. The major components of the meaning system are meaning assignment tendencies which form patterns underlying emotions, cognitions, cognitive acts, and meanings. Specifically we will demonstrate how four different aspects of place attachment are related to patterns of meaning assignment tendencies. These are: (i) preferences for open or closed places versus no preferences, which indicates noting the physical structure of places (ii) grasping special atmosphere of places (holiness, romantic atmosphere) which indicates addressing the emotional characteristics of locations; (iii) matching specific behavior and actions to specific places (e.g., some places are more adequate for specific actions than others) which indicates noting actional aspects of places; and (iv) caring about (grasping, knowing) orientation in space, which reflects a functional approach to places. These four issues constitute a sample of major concerns of the meaning of places that would serve for testing the hypothesis of this study. We expect each of the aspects to be related to a unique pattern of the meaning assignment tendencies assessed in terms of the meaning system.

In order to better understand the processes underlying place attachment, we have applied the model of meaning [20]. According to this model, cognitions manifested as beliefs, judgments, attitudes, emotional predispositions and preferences are a function of basic information processing tendencies which enable identifying inputs and determining their meaning. Since attachments have a variety of manifestations, the meaning model seemed as the most adequate theoretical approach for studying attachments.

\section{LITERATURE REVIEW}

\section{Place Attachment}

By interacting with their environments people develop bonds and links. In the course of this interaction, anonymous spaces turn into places endowed with meaning which serve as objects of attachment [21]. Attention has increasingly been directed in the domains of human geography and environmental psychology to the study of place attachment. This concept has been related to psychological and physical features [22], and to variables concerned with feelings, emotions, and bonds that people develop toward places where they live [23, 24]. Pretty et al. [25] and Groat [26] proposed that individual relations with places endow them with meaning and order by means of personal, social, and cultural processes. Riger and Lavrakas [27] reported two particular characteristics of place attachment that relate to rootedness and bondedness. While rootedness has to do with length of residence, possession of home, and expectations to reside in the same place, bondedness is associated with belonging to and familiarity with the place.

Emotion was shown to have a deep influence on the links that people establish with particular environments. Tuan [21] suggested that emotion is a major aspect by means of which people endow environments with meaning. Eisenhauer et al. [28] showed how interaction with certain natural environments contributed to the development of emotional attachment to those settings. Casakin and Billig [29], Jorgensen and Stedman [7, 30], and Kyle et al. [31] found that affective attachment received higher scores as compared to other dimensions of attachment (i.e. place identity and place dependence).

The emotional bond to places is promoted also by the social bonding. Moore and Graefe [32], and Kyle et al. [29] showed that leisure environments facilitate a desire for leisure experiences. The importance of social bonds to place was reported in the environmental psychology literature by a number of investigators (e.g., Altman and Low) [33]. Social relationships were likely to be influenced by the physical context where they developed. Also Hidalgo and Hernandez [34] found that social attachments were stronger than place attachments.

Emotions are intimately related to cognitions. Prominent researchers in the environmental psychology field operationalized place cognition in terms of place identity. Place identity is of particular importance in the domains of human geography and environmental psychology. Proshansky [35] perceived place identity as the cognitive connection established between the self and the environment, indicating that places reflect components of people's own identities. Accordingly, environments are conceived as an inseparable part of the self. This conceptualization resembled the suggestion propounded by Jorgensen and Stedman [7] who viewed place identity as part of a more general self-identification. Dixon and Durrheim [36] added that identity is not a fixed notion, but is rather representative of how a sense of self develops by means of an interaction between people and a physical environment. Rootedness [21] and existential insideness [37] were expressions used by human geographers to reflect on major aspects of place identity.

According to the theoretical conception of this paper, meanings and the processes of meaning assignment are the formative constituents of place attachment.

\section{Meaning: The Theory and the System}

This study focuses on identifying the information processing tendencies underlying meanings attributed to places. For this purpose a brief introduction presenting the meaning theory and system are necessary.

Meaning is sets of cognitive contents used for defining, expressing and communicating significance for a variety of purposes, e.g., identifying inputs, problem solving, comprehension, or communication. Meaning consists of meaning units, which include two components: 'the referent' which is the input, the stimulus, or the subject to which meaning is assigned, and 'the meaning value' which is the cognitive contents designed to express or communicate the meaning of the referent. The following are five examples of meaning units: "Paris - is in France", "Wine - is on the table", "Flower - is a plant", "Bottle - is made of glass". In these meaning units, 'Paris', 'Wine', 'Flower' and 'Bottle' are the referents and 'is in France', 'is on the table' 'is a plant' and 'is made of glass' are the meaning values. Each meaning unit may be characterized in terms of meaning variables of the five following classes: meaning dimensions - which characterize the contents of the meaning values (e.g., locational qualities, material), types of 
relation - which characterize the immediacy of the relation between the referent and the meaning value (e.g., attributive, exemplifying-illustrative, metaphoric-symbolic), forms of relation - which characterize the logical-formal properties of the relation between the referent and the meaning value (e.g., positive, conjunctive, partial), shifts of referent - which characterize the relations of the present referent to the initial input and previous referents (e.g., identical, partial, opposite), and forms of expression - which characterize the media of expression of the referent and/or the meaning value (e.g., verbal, graphic, motional). For example, when the input is Neighborhood and an individual's statement of the meaning of neighborhood is "The neighborhood is big", the meaning unit is "Neighborhood - is big" and this meaning unit is coded in the following manner: Meaning dimension: size and dimensions, Type of relation: attributive, Form of relation: declarative positive, Shift of referent: identical to input, and Form of expression: verbal. The meaning system consists of the whole set of the meaning variables (see Table 1).

Each of the five sets of meaning variables is complete in itself and defined separately of the other sets. Thus, characterizing a meaning unit involves using one variable from each set. Hence, when we have a several meaning units characterized in terms of meaning variables and we count the frequencies of meaning variables used in characterizing these meaning units, we get in fact five sets of frequencies, that is, one for meaning dimensions, one for types of relation, one for forms of relation, one for shifts of referent, and one for forms of expression. Each of these five groups of frequencies amounts to the same total but consists of different meaning variables.

The description of the components of meaning indicates that it is a system, that it is complex, and that its elements are defined in terms of other elements of the system (namely, it is self-embedded and regressive). These three characteristics reflect the static or structural aspects of the system. They are complemented by three further properties that describe the dynamic characteristics of meaning: it is a developing system in the ontogenetic sense; it is a selective system dependent in its structure and functioning on properties of the individual and the input; and it is a dynamic system, whose special characteristics become manifest when it is activated for meaning assignment.

Each individual disposes over a certain selected part of the meaning system which represents the particular tendencies of that individual to apply the meaning system in information processing. Thus, each individual tends to use specific meaning variables with higher frequency and other meaning variables with medium or low frequency. The frequencies with which the individual tends to use each meaning variable are assessed by means of The Meaning Test and constitute the individual's meaning profile (see Method).

The major and most essential function of meaning is input identification [38]. This function is implemented by providing the contents and processes enabling meaning assignment to inputs. Input identification ranges from limited identification in terms of a stimulus for a particular action to highly complex meaning elaborations necessary for acts involving cognitive, emotional, physiological and behavioral components [18].

Another function of the meaning system is to provide the cognitive contents and processes necessary for carrying out different cognitive acts. Studies showed that each meaning variable represents a specific set of contents and processes.

For example, the meaning dimension Locational Qualities represents the set of contents denoting location (e.g., special, geographic) and the processes involved in dealing cognitively with locations (e.g., identifying, specifying, recalling, transforming locations). Further studies showed that each type of cognitive act corresponds to a specific pattern of meaning variables that provide a description of the contents and processes involved in its enactment. For example, meaning variables involved in planning are concerned with structure, temporal qualities, and causes and antecedents [39-41]. If the individual's meaning profile includes a sufficient proportion of the meaning variables considered in the pattern corresponding to the particular cognitive act, that individual will be able to perform well the particular cognitive act [18, $19,42]$.

A third function of the meaning system is manifested in the domain of personality. A body of research showed that each of over 300 personality traits, i.e. personality tendencies and characteristics, such as independence, avarice or sentimentality corresponds to a specific pattern of meaning variables. Again, as in the case of cognitive acts, the pattern of meaning variables may be seen as providing a description of the contents and processes involved in the enactment of the specific trait. For example, the meaning variables in the pattern corresponding to extraversion are characterized by high salience of the meaning dimensions of action, sensory qualities, temporal qualities and belongingness of objects, as well as low salience of the meaning dimensions of internal sensations and cognitive qualities $[18,43]$. If the individual's meaning profile includes a sufficient proportion of the meaning variables found also in the pattern corresponding to the particular personality trait, it is highly likely that the individual scores high on that personality trait.

The same holds in regard to further tendencies in the domain of personality, such as personality dispositions, defense mechanisms, the self, and emotions [41, 44, 45].

In sum, the described functions of the meaning system indicate that the meaning system provides the understructure that is, the raw materials in terms of contents and processes for input identification, cognitive functioning, personality tendencies and emotions. All four functions depend on meaning assignment and reflect the central role of meaning for and within cognition. This has given rise to the conceptualization of cognition as a meaning-processing and meaningprocessed system

\section{Meaning Variables and Place Attachment: Initial Indica- tions}

The study presented in this paper is grounded in the conception that meaning plays an important role in regard to 
Table 1. Variables of the System of Meaning

\begin{tabular}{|c|c|c|c|}
\hline \multicolumn{4}{|c|}{ Meaning Dimensions (DIM) } \\
\hline 1 & Contextual allocation & 13 & Size and dimensionality \\
\hline \multirow{2}{*}{2} & \multirow{2}{*}{ Range of inclusion: a. Subclasses; b. Parts } & 14 & Quantity and number \\
\hline & & 15 & Locational qualities \\
\hline 3 & Function, purpose and role & 16 & Temporal qualities \\
\hline 4 & $\begin{array}{l}\text { Actions and potentialities for action: } a \text {. By referent; b. To/with } \\
\text { referent }\end{array}$ & 17 & Possession: a. By referent ; b. Of referent (belongingness) \\
\hline 5 & Manner of occurrence and operation & 18 & Development \\
\hline 6 & Antecedents and causes & \multirow{2}{*}{19} & \multirow{2}{*}{ Sensory qualities-d: a. Of referent; b. Perceived by referent } \\
\hline 7 & Consequences and results & & \\
\hline 8 & $\begin{array}{l}\text { Domain of application: a. Referent as subject; b. Referent as } \\
\text { object }\end{array}$ & 20 & Feelings and emotions: a. Evoked by referent; b. Experienced by referent \\
\hline 9 & Material & \multirow{2}{*}{21} & \multirow{2}{*}{ Judgments and evaluations: $a$. About the referent; $b$. Held by the referent } \\
\hline 10 & Structure & & \\
\hline 11 & State and changes in state & \multirow{2}{*}{22} & \multirow{2}{*}{ Cognitive qualities: a. Evoked by referent; b. characterizing the referent } \\
\hline 12 & Weight and mass & & \\
\hline \multicolumn{4}{|c|}{ Types of Relation-a (TR) } \\
\hline 1 & Attributive: a. Qualities to substance; $b$. Actions to agent & 3 & Exemplifying-Illustrative: a. Instance; b. Situation; c. Scene \\
\hline 2 & $\begin{array}{l}\text { Comparative: a. Similar; b. Different; c. Complementary; d. } \\
\text { Relational }\end{array}$ & 4 & $\begin{array}{l}\text { Metaphoric-Symbolic: a. Interpretation; b. Conventional metaphor; c. } \\
\text { Original metaphor; d. Symbol }\end{array}$ \\
\hline \multicolumn{4}{|c|}{ Forms of Relation-b (FR) } \\
\hline 1 & Propositional: 1a positive; $1 \mathrm{~b}$. negative & 5 & Disjunctive: 5 a positive; $5 \mathrm{~b}$. negative \\
\hline 2 & Partial: $2 \mathrm{a}$ positive; $2 \mathrm{~b}$ negative & 6 & Normative (obligatory): 6 a positive $6 \mathrm{~b}$ negative \\
\hline 3 & Universal: 3 a positive; $3 \mathrm{~b}$ negative & 7 & Questioning: 7a positive $7 \mathrm{~b}$ negative \\
\hline 4 & Conjunctive: $4 \mathrm{a}$ positive $4 \mathrm{~b}$ negative & 8 & Desired: 8a positive; $8 \mathrm{~b}$ negative \\
\hline \multicolumn{4}{|c|}{ Shifts of Referent-b (SR) } \\
\hline 1 & Identical & 8 & Linguistic label \\
\hline 2 & Opposite & 9 & Grammatical variation \\
\hline 3 & Partial & 10 & Former meaning values combined \\
\hline 4 & Input + addition & 11 & Superordinate \\
\hline 5 & Former meaning value & \multirow{2}{*}{12} & \multirow{2}{*}{ Synonym a. Original language; b. Translated; c. Other medium } \\
\hline 6 & Associated on same level & & \\
\hline 7 & Unrelated & 13 & Former implicit meaning value \\
\hline \multicolumn{4}{|c|}{ Forms of Expression (FE) } \\
\hline 1 & verbal & 4 & Auditory \\
\hline 2 & Graphic & 5 & Object or situation \\
\hline 3 & Motor & & \\
\hline
\end{tabular}

${ }^{a}$ Modes of meaning: Lexical mode: TR1+TR2; Personal mode: TR3+TR4

${ }^{\text {b }}$ Close SR: $1+9+12$ Medium SR: $3+4+5+6+10+11$ Distant SR: $2+7+8+13$

${ }^{\mathrm{c}}$ Each of the FEs has three forms: a. Direct; b. Described; c. By means of available materials.

${ }^{\mathrm{d}}$ This meaning dimension includes a listing of subcategories of the different senses/sensations that may also be grouped into "external" and "internal".

place attachment. As noted above, several considerations have led to the hypothesis that the meaning system may constitute the adequate tool for assessing place attachment. One consideration was that place attachment includes various cognitions in regard to a place, whereby each cognition is likely to be a function of information processing tendencies, as has been shown in previous studies concerning other cog- nitions - e.g., $[7,5,33]$. Another consideration was that place attachment has often been attributed to the meaning of the place, which indicates that information processing tendencies of the kind assessed by the test of meanings are likely to be involved. A third consideration was that the meaning system would enable to coordinate the variety of issues that investigators have identified in the construct of place at- 
tachment, viz. emotions, cognitions, meanings and personality correlates. Notably, the commonly assessed aspects of place attachment can be readily expressed in terms of the meaning system.

The present study is designed to identify the meaning profiles of several place attachment cognitions. Identifying these meaning profiles would provide information about the relevant cognitive processes that are to be tapped in order to promote certain place attachment cognitions that play a role in environmental planning and other environment-bound actions. Since place attachments are so intimately bound to cognitions, we focused in this study only on meaning dimensions that represent most clearly the content aspect of meanings.

\section{STUDY}

The purpose of this research was to identify the meaning profiles of several components of place attachment. These are: preferences for open or closed spaces versus no preferences; grasping special atmosphere of places versus not grasping; matching of actions to locations or not matching; and orientation in space. The expectation was that the four issues would each be related to a different set of meaning variables and that these meaning variables would shed light on the processes underlying the particular studied cognitions.

\section{METHOD}

\section{Participants}

The participants were 36 students of both genders (20 men and 16 women) in the second to fourth years of their academic studies in architecture, in the age range of 22 to 27 years $($ Mean $=24.4, \mathrm{SD}=1.2$, who consented to participate in the study. No payment was offered for participation.

\section{Instruments}

The participants were administered two questionnaires. One questionnaire dealt with place attachment and included items related to preferences for open or closed spaces versus no preferences; grasping special atmosphere of places versus not grasping; matching of actions to locations or not matching; and orientation in space. Each question was followed by four response alternatives, scored as 1 to 4 . The other questionnaire was the standard Meaning Test [20] in which students were requested to communicate to someone of their choice (who understands language etc. but not the meaning of the specific stimuli) the interpersonally-shared and personal-subjective meanings of 11 standard stimuli, using any means of communication they consider adequate (write, draw, describe drawings or objects, etc.).

\section{Procedure}

The two questionnaires were administered in class sessions, on two separate occasions, two weeks apart. Part of the participants got the Meaning Test first, and the others as second. The two questionnaires were administered and scored independently of each other. At the time of the testing, none of the participants, the test administrators or the test coders knew the objectives of the study. The scores provided by the place attachment questionnaire consisted of the raw scores of the responses checked by the participants. Each participant got 4 separate scores: one for preferences for open or closed spaces versus no preferences; one for grasping special atmosphere of places versus not grasping; one for matching of actions to locations or not matching; and one for orientation in space. The coding of the Meaning Test consisted in identifying in the responses meaning units, each of which was characterized in terms of one variable of each of the five classes of variables (i.e., meaning dimensions, types of relation), which were then summed so that the whole set of sums yielded the meaning profiles of each individual participant. The reliability of coding across two different coders was satisfactory (correlation coefficients for two coders for the different meaning variables ranged in previous studies from $r=.87$ to $r=.92$ ) $[19,20,39]$. In the present study the reliability across two coders was $\mathrm{r}=.95$ for all coded meaning variables.

The relation between the two sets of data - the place attachment scores and the meaning profiles - was calculated in the following manner: the scores on each of the four place attachment items were split at the median so that on each of these items a participant was either above the median or below it. The two groups of participants on each of the four items were compared independently in terms of the means of the meaning variables based on the participants' meaning profiles. As noted earlier, in this study we focused only on comparisons of the meaning dimensions. The comparisons were done by t-test for independent samples. In view of the large number of comparisons, we used the Bonferroni criteria and considered only findings that turned out to be significant at $<.001$ level. The t-test statistic was preferred to correlation coefficients because it reduces to some extent the impact of extreme values in the data.

\section{RESULTS}

The mean comparisons presented in Table 2 show that each of the four notions of place attachment on which this study focused corresponds to a specific pattern of meaning dimensions. This confirms the expectation that place attachment components are grounded in individual information processing tendencies and hence may be accessed through these tendencies. The range of variables in the different patterns runs from three to six. In view of previous findings [20], the range indicates that the studied issues are actually attitudes rather than personality traits or cognitive acts. In contrast to personality traits that are stable and broad ranged tendencies characteristic of the person, and cognitive acts that are broad ranged but context bound, attitudes are much more limited and specific in range and application. Further, despite some overlapping in meaning dimensions, the patterns appear to be unique. This indicates that although the four aspects share the common theme of place attachment, they are different and distinct.

The findings show that individuals who have a preference for the degree to which spaces are open, namely, those who prefer either open or closed spaces in contrast to those who do not care about this feature of space, apply for meaning assignment of inputs in general more often the content categories of locational qualities, state of the input, and the 
Table 2. Significant Differences in Meaning Dimensions between High and Low Scorers on the Different Aspects of Place Attachment

\begin{tabular}{|c|c|c|c|c|}
\hline Place Attachment Item & Meaning Dimension & Mean of High Scorers & Mean of Low Scorers & t-Test \\
\hline \multirow{2}{*}{$\begin{array}{l}\text { Preference for open or closed } \\
\text { spaces } v s \text { no preference }\end{array}$} & Locational qualities & 5.43 & 1.28 & $3.88 * *$ \\
\hline & Evoked emotions & 5.66 & 3.25 & $3.79 *$ \\
\hline \multirow[t]{4}{*}{ Grasping special atmosphere } & Locational qualities & 5.49 & 2.35 & $3.70 *$ \\
\hline & Emotions (experienced and evoked) & 7.37 & 4.10 & $6.36 * * *$ \\
\hline & Experienced sensory qualities & 6.14 & 3.33 & $4.82 * * *$ \\
\hline & Function, purpose and role & 2.85 & 6.24 & $4.59 * * *$ \\
\hline \multirow[t]{2}{*}{ Matching actions } & Locational qualities & 5.12 & 2.10 & $6.32 * * *$ \\
\hline & Domain of application (as subject) & 7.72 & 4.46 & $3.90 * *$ \\
\hline \multirow[t]{6}{*}{ Orientation in space } & Locational qualities & 4.37 & 2.11 & $3.70^{*}$ \\
\hline & Quantity and number & 2.68 & 0.44 & $4.10 * *$ \\
\hline & Size and dimensions & 3.63 & 0.87 & $4.14 * *$ \\
\hline & Structure & 3.37 & 0.56 & $4.79 * *$ \\
\hline & Cognitive qualities (evoked by referent) & 4.89 & 2.11 & $3.90 * *$ \\
\hline & Cognitive qualities (of referent) & 3.93 & 1.10 & $3.76^{*}$ \\
\hline
\end{tabular}

${ }^{*} \mathrm{p}<.001{ }^{* *} \mathrm{p}<.0005^{* * *} \mathrm{p}<.0001$

emotions evoked by the inputs. In other words, they notice and focus naturally on where the input is, what is the state of the input (e.g., its strength, openness, health, stability etc.), and the emotions it evokes in oneself.

Individuals who grasp the special atmosphere of places and care about this characteristic of places differ from those who do not grasp the atmosphere in the meaning dimensions of locational qualities, judgments and evaluations, emotions (both those experienced by the referent and evoked by it), and sensory qualities (e.g., color, form, temperature, humidity, sound, odor) which they use more than the others, and in the meaning dimension of function which they apply less than the others.

Further, those who care about matching actions to places versus those who think any action can be performed anywhere, apply more than the others the meaning dimensions of locational qualities and judgments and evaluations, but also the meaning dimensions of actions, functions, and range of applications. This shows that for input identification and in thinking in general they consider locations, they perform evaluations, they focus on actions and functions, and consider who is involved in the situation or functions in it.

Finally, caring about orientation in space corresponds to a pattern of meaning dimensions that includes in addition to locational qualities also further meaning dimensions that did not figure in the previously considered aspects of place at- tachment: size and dimensions, structure, quantity and number and cognitive qualities concerning the input. Hence, those who care about orientation in space focus on the location of an input, its size, quantity, structure and the ideas and memories it evokes.

\section{DISCUSSION}

The findings of the study indicate first, that different aspects of place attachment correspond to attitudes and second, that they are rooted in individual tendencies that underlie meaning assignment specifically, and contribute to shaping cognitive and emotional functioning in general. Hence place attachment seems to be an integral part of the individual's personality.

The components that make up each of the patterns allow for conclusions about how to access the studied aspects and influence on them, if it is so desired. For example, if one wants to make people more sensitive to the openness of spaces, it would be advisable to sensitize them to locations in general, and in addition to the state of inputs and to emotions evoked by inputs. When the aim is to increase the individual's responsiveness to the particular atmosphere characteristic of certain place, it would be desirable to make that person aware of the sensory qualities of the place, such as its color, morphology, sound, etc., or to focus on the emotions experienced and evoked by that place. Regarding matching actions to places, it would be recommendable to sensitize individu- 
als to locational qualities of the place, such as where the place is situated, what is close to it, how can we get there, functions and activities that are carried out there, as well as who are the people that are concerned with those actions. Similarly, for orientation in space it would be advisable to focus on the external aspects of inputs - including structure, size, quantity and the cognitions and memories of the person himself or herself.

\section{CONCLUSIONS}

It is of special interest to note that the findings of the study allow for shaping place attachments of individuals in an indirect manner, focusing on the underlying meaning dimensions rather than directly on the explicit attitudes themselves. In terms of the suggested place attachment categories we can say that independently of the place attachment component, location was the meaning dimension most frequently related to notions of place attachment. Therefore, the location dimension is the most influential aspect of place attachment. Whenever we want to shape the attitude toward any place we should talk "location" - describe exactly where it is, how it looks from different perspectives, how to get there, near what it is, what locations can be seen from there. This means that above all possible meaning dimensions, location will be the stronger variable that will affect the way people are disposed to interact with their environments. The environmental design literature is full of examples describing interactions between people and environments characterized by successful locational aspects of a place. In consequence, it is advisable that the location dimension will be considered by designers and planners as a critical aspect of their designs. Attention paid to environmental features concerned with place location, will result in designs of higher quality and appeal.

Emotion was the second meaning dimension related to place attachment. It is to be noted that emotion in the meaning system is a representation of emotion, not the experience itself. The meaning dimension emotion shows that the person thinks about emotion, considers it, notices it, takes it into account in his thinking and decisions, that he or she has the cognitive tools of handling emotions and probably regulating it.

In consequence, in order to shape the attitude toward any place one should consider emotions that are experienced and evoked by that place. What we learn from this is that above all possible meaning dimensions, emotion will be one of the stronger variables affecting the way individuals are disposed to interact with their environments. The issue of how certain characteristics of the environment elicit specific emotions, and impede or inhibit others is of much interest to designers and planners. A question that so far has not been addressed in this study is how can environmental designers manipulate or influence the emotions elicited by their designs. Is it possible to predict how emotional responses are evoked by certain environments? In a further study which is under way we will attempt to answer this question by investigating whether different clusters of emotions are more often elicited by certain types of environments.

\section{REFERENCES}

[1] Ponzetti, J. Growing old in rural communities: a visual methodology for studying place attachment. Journal of Rural Community Psychology 2003; [cited 2008 March 10]; About 26 screens. Available from: http://www.marshall.edu/jrcp/E6one_Ponzetti.htm.

[2] Lalli M. Urban-related identity: theory, measurement and empirical findings. J Environ Psychol 1992; 12: 285-303.

[3] McAndrew RT. The measurement of rootedness and the prediction of attachment to home-towns in college students. J Environ Psychol 1998; 18: 409-417.

[4] Marcus CC. Environmental memories. In: Altman I, Low SM, editors. Place attachment. NY: Plenum Press; 1992. p. 87-112.

[5] Low S. Symbolic ties that bind: place attachment in plaza. In Altman I., Low S., editors. Place Attachment. NY: Plenum Press; 1992. p. 279-304.

[6] Milligan M. Interactional past and potential. Symbolic Interaction, 1998; 21:1-33.

[7] Jorgensen BS, Stedman, RC. Sense of place as an attitude: lakeshore property owners' attitudes toward their properties. J Environ Psychol 2001; 21: 233-248.

[8] Fuhrer U, Kaiser F. Bindung an das zuhause: die emotionalen ursachen. Zeitschrift fr Sozialpsychologie 1992; 10: 5-18.

[9] Guillian MV, Feldman R. Place attachment in a developmental and cultural context. J Environ Psychol 1993; 13: 267-74.

[10] Gustafson P. Meanings of place: everyday experience and theoretical conceptualizations. J Environ Psychol 2001; 21: 5-16.

[11] Eisenhauer BW, Krannisch RS, Blahna DJ. Attachments to special places on public lands: an analysis of activities, reasons for attachments, and community connections. J Soc Natur Resour 2000; 13: 421-441.

[12] Kyle GT, Mowen AJ, Tarrant, M. Linking place preferences with place meaning: an examination of the relationship between place motivation and place attachment. J Environ Psychol 2004; 24: 439454.

[13] Hummon DM. Community attachment: local sentiment and sense of place. In: Altman I, Low SM, editors. Place attachment. New York: Plenum Press; 1992. p. 253-278.

[14] Giuliani MV. Towards an analysis of mental representations to the home. J. Archit Plann Res 1991; 8: 133-146.

[15] Manfredo M.J, Driver BL., Tarrant, MA. Measuring leisure motivation: a meta analysis of the recreation experience preference scales. J Leisure Res 1996; 28: 245-249.

[16] Fullilove, MT. Psychiatric implications of displacement: contributions from the psychology of place. Am J Psychiatry 1996; 153: 1516-23.

[17] Twigger-Ross CL, Uzzell DL. Place and identity processes. J Environ Psychol 1996; 16: 205-220.

[18] Kreitler S, Kreitler, H. The psychosmenatic foundations of comprehension. Theor Linguist 1985; 12: 185-195.

[19] Kreitler S, Kreitler H. Motivational and cognitive determinants of exploration. In: Keller H, Schneider K, Henderson B, editors. Curiosity and exploration. New York: Springer-Verlag; 1994. p. 259284.

[20] Kreitler S, Kreitler H. The cognitive foundations of personality traits. New York: Plenum Publishing Corporation; 1990.

[21] Tuan, YF. Space and place: the perspective of experience. Minneapolis: University of Minnesota Press; 1977.

[22] Bonnes M, Secchiaroli G. Environmental psychology: a psychosocial introduction. London: Sage; 1995.

[23] Bagozzi RP. The construct validity of the affective, behavioural and cognitive components of attitude by analysis of covariance structures. Multivariate Behav Res 1978; 13: 9-31.

[24] Hay R. Sense of place in development context. J Environ Psychol 1998; 18: 5-29.

[25] Pretty G, Chipuer HM, Bramston P. Sense of place among adolescence and adults in two rural Australian towns: the discriminating features of place attachment, sense of community and place dependence in relation to place identity. J. Environ Psychol 2003; 23: 273-287.

[26] Groat L. Introduction: place, aesthetic evaluation and home. In: Groat L, editor. Giving places meaning. San Diego (CA): Academic Press; 1995. p. 1-26.

[27] Riger S, Lavrakas P. Community ties: patterns of attachment and social interaction in urban neighborhoods. Am J Community Psychol 1981; 9: 55-66. 
[28] Eisenhauer BW, Krannich RS, Blahna DJ. Attachments to special places on public lands: an analysis of activities, reason for attachments, and community connections. Soc Nat Resour 2000; 13: 421441 .

[29] Casakin, H. and Billig, M. Submitted to Environment and Behavior 2008.

[30] Jorgensen BS, Stedman RC. A comparative analysis of predictors of sense of place dimensions: attachment to, dependence on, and identification with lakeshore properties. J Environ Manage 2006; 79: 316-327.

[31] Kyle GT, Graefe A, Manning R, Bacon J. Effects of place attachment on users' perceptions of social and environmental conditions in a natural setting. J Environ Psychol 2004; 24: 213-225.

[32] Moore RL, Graefe AR. Attachments to recreation settings: the case of rail-trail users. Leisure Sci 1994; 16: 17-31.

[33] Altman I, Low S. Place Attachment. Plenum Press: New York; 1992.

[34] Hidalgo MC, Hernandez B. Place attachment: conceptual and empirical questions. J Environ Psychol 2001; 21: 273-281.

[35] Proshansky HM. The city and self-identity. Environ Behav 1978; 10: $147-169$

[36] Dixon J, Durrheim K. Dislocating identity: desegregation and the transformation of place. J. Environ Psychol 2004; 24: 455-473.

[37] Relph E. Place and placelessness. London: Pion; 1976.

[38] Kreitler S, Kreitler H. Meaning assignment in perception. In: Froehlich WD, Smith GJW, Draguns JG, Hentschel U, editors.
Psychological processes in cognition and personality. Washington (DC): Hemisphere Publishing Corporation/McGraw-Hill; 1984. p. 173-191.

[39] Kreitler S, Kreitler H. Individuality in planning: meaning patterns of planning styles. Int J Psychol 1986, 21: 565-587.

[40] Kreitler S, Kreitler H. The motivational and cognitive determinants of individual planning. Genet Soc Gen Psychol Monogr 1987, 113: 81-107.

[41] Kreitler S, Kreitler H, Psychosemantic aspects of the self. In: Honess TM, Yardley, KM, editor. Self and identity: individual change and development. London: Routledge \& Kegan Paul; 1987. p. 338 358 .

[42] Kreitler S, Kreitler H. Horizontal decalage: a problem and its resolution. Cogn Dev 1989; 4: 89-119.

[43] Kreitler S, Kreitler H. The paranoid person: cognitive motivations and personality traits. Eur J Personal 1997; 11: 101-132.

[44] Kreitler S. Dynamics of fear and anxiety. In: Gower PL, editor. Psychology of fear Hauppauge. NY: Nova Science Publishers; 2003. p. 1-15.

[45] Kreitler S, Kreitler $H$. The cognitive determinants of defense mechanisms.In: Hentschel U, Smith G, Ehlers W, Draguns JG, editors. The concept of defense mechanisms in contemporary psychology: theoretical, research and clinical perspectives. New York: Springer-Verlag; 1993. p. 152-183.

(C) Casakin and Kreitler; Licensee Bentham Open.

This is an open access article distributed under the terms of the Creative Commons Attribution License (http://creativecommons.org/license/by/2.5/), which permits unrestrictive use, distribution, and reproduction in any medium, provided the original work is properly cited. 